\title{
XVIII. Osteological description of the one-horned rhinoceros
}

\section{Cuvier}

To cite this article: Cuvier (1804) XVIII. Osteological description of the one-horned rhinoceros, Philosophical Magazine Series 1, 20:78, 111-120, DOI: 10.1080/14786440408676608

To link to this article: http://dx.doi.org/10.1080/14786440408676608

曲 Published online: 18 May 2009.

Submit your article to this journal $\pi$

ЏII Article views: 3

Q View related articles $\asymp$ 
America, the husband is nursed for some days after his wife has brought forth. Among the Runsians homicide is almost considered as a matter of indifference; but among the Eslenes it is punished with death. Both tribes observe nearly the same funeral ceremonies; but among one of them, whatever property is left by the deceased is divided among his relations; among the other, all the friends bring, as a farewell offering, some articles of furniture, which are interred with him.

It is very remarkable, that two tribes so near to each other and so similar in some respects should be so different in others: this difference is particularly remarked in their languages; between which the ablest etymologists would scarcely find the slightest relation.

\section{Osteological Description of the one-horned Rhincs ceros, by Cuvier. \\ [Continuẹd from our last volume, p. 354.] 2d, The Teeth.}

A xnowledge of the number and position of the teetl, but particularly of the changes which take place in their figure at different ages, is of the greatest importance in the study of the nature of animals in general, but especially in researches respecting those species to which the fossil bones have belonged. I have therefore paid more attention to this part than to any other.

This was necessary in a particular manner in regard to the rhinoceros. The want of proper observations had occasioned a variation among naturalists in this respect; and M. Faujas, the last person who examined it, has only increased our doubts : a regard for truth has induced me to rectify what he has said on this subject.

My observations are the more necessary, as this learned geologist had deduced, from facts seen in a wrong point of view, conclusions subversive of those bases on which the systems of zoölogy are founded. But those who are not in a situation to verify the facts in question; and who, on the other hand, are unacquainted with the rational foundations of our systems, may too readily adopt conclusions advanced by a naturalist of so great authority, which would remove still to a greater distance the epoch when the real principles of zoology will be universally acknowledged.

I shall ubserve then in general, that at the rhinoceroses have seven molar teeth on each side, both in the upper and lower jaw, making twenty-eight all together. 
The head of the two-horned rhinoceros in our museum exhibits indeed only twenty, apparently on account of the age of the individual to which it belonged: but anatomists are not deceived in these cases, because they know how to find in the cells at the bottom of the jaw-bone, the germs of the teeth which have not yet appeared; and these germs have really existed in this head, which would have had twenty-eight teeth, like all those of its species, had not the animal been killed too young.

The skeleton of the one-horned rhinoceros, which forms the principal part of the present description, exhibits also, it is true, on one side of the lower jaw six teeth or stumps of teeth, and on the other seven ; but this is only an appearance which cannot deceive when one has studied the laws of the growth of teeth, especially according to the method of Tenon.

All herbivorous animals, beginning with the horse, wear their teeth to the very roots, because, in proportion as the crown is diminished by trituration, the alveolus fills up and pushes the tooth outwards. When this root is composed of two branches, as in the rhinoceros, and the shank of the tooth is completely worn, there remain two stumps of the root : these stumps drop out one after the other, always lessened by trituration and pushed outwards by the increase of the bone in the interior of the alveolus. At length, however, the alveoli themselves become entirely effaced.

This is what in part took place in the rhinoceros in question. It had already lost its two molar teeth, and the alveoli were almost entirely effaced; the detrition of the two following ones had been extended to the roots, and it had even lost on one side one of the stumps of the roots, while those of the other side both remained.

Besides, no animal has nor can have an odd number of teeth, considering the symmetry of the sides of the head, and the suture which dividing the maxillary bones prevents them from having an alveolus in the middle. Thus, when one troth more is found in the one side than in the other, one is added in imagination to the latter.

But if this rhinoceros had lost its molar teeth by age, it had not gained incisors. This is not the case with it, nor with other animals which grow old. The two small intermediate incisors of the lower jaw exist at a young age, as is: seen by the head given to the cabinet of M. Adrian Camper; and still better by the end of the lower jaw of a very young subject. drawn by his father, and inserted in the Transactions of the Imperial Academy of Sciences at 
St. Petersburgh for $1777^{*}$; but they remain at all times concealed under the gum, and this is the reason why Meckel did not see them in the living animal, while they showed themselves in the skeleton. Mr. Thomas, a surgeon of London, who has published some anatonical observations on the one-horned rhinoccros, also found these small teeth in the skeleton of an individual four years of age.

But what no one, as far as I know, has ever yet published is, that the rhinoccros, during a certain period of its life, has two similar incisors in the upper jaw, only they are without the large ones, while in the lower jaw they are among the large ones. This, indeed, might be concluded from the drawing of the intermaxillary of the very young rhinoceros given by Camper the father in the Transactions before mentioned t. I cven at first conceived that these bones must necessarily have been produced by another species.

But on examining the anatomical drawings of our rhinoceros, made with the greatest care by Marechal under the inspection of Viq-d'Azir and De Mertrud, I observed the figure of a very small tooth without the large upper incisor of the right side; and I saw in the explanation which accompanies that drawing, and which is by Viq-d'Azir, that there was indeed on that side a small tooth which was wanting in the other. I examined the skeleton, and found on one side the remnant of an alveclus, but the tooth, already too much extirpated, had been lost at the time of maceration; on the other side the alveolus even had been effaced.

It may be readily scen that all these observations prove nothing dgainst the importance which characters taken from the teeth have in zoölogy; but to employ their number, for example, as a character, we must no doubt take the proper precautions to ascertain what it is, and in general to obtain all the preliminary knowledge that may be necessary. One will not then be in danger of creating species which never existed, - a fault which would be attended with as bad consequences in the simple history of animals and in its systems as in geology ; for, if natural history requires truth, it is above all in those parts which are entirely conjectural $t$.

After this necessary digression I shall return to my subject, and continue to describc the teeth of my rhinoceros.

To obtain a complete knowledge of the teeth of herbivorous animals, it is not enough to have seen them at one period of life, as these teeth are continually wearng down; the figure

$$
\text { * Plite iz. fie. } 3 . \quad+\text { Plate Jx. fig. } 2 .
$$

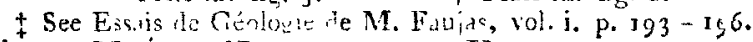

Vol. 20. No. 78. Nou. 1804. 
of their crown is also in a continual state of change ; and the naturalist must follow them from the moment when they pierce the gum to that when they fall out of the mouth.

But it is not aliways necessary for this purpose to have at one's disposal individuals of all ages. As the fore-teeth appear sooner, they are also sooner worn; and one may often follow in one jaw all the degrees of detrition proceeding from the posterior to the anterior teeth.

The following, then, are the appearances observed in the teeth of the rhinoceros:-The base or neck of the tooth is quadrangular; the interior and posterior side are a little shorter than the anterior and exterior; consequently the latter intercept an acute angle, and the others an obtuse. On this base, supposing the side of the root turned down, arise eminences the summit of which is sharp and entirely covered with enamel. As long as the tooth is not worn, one of these eminences fits exactly the exterior edge of the tooth, or rather forms it: it has a vertical rib projecting towards the anterior third.

The second eminence is towards the anterior edge: it is joined to the first at the anterior external angle; then inclines towards the interior anterior, but proceeding a little more backward than the anterior edge of the base.

The third eminence arises from the posterior third of the first; proceeds directly inwards, then bifurcates : one of its branches proceeds forwards and the other obliquely backwards towards the interior posterior.

These sharp eminences, at a considerable distance from each other at their summits, have broad bases which touch each other. The first effect of detrition is to wear off the enamel from the summit, and to discover every where a line of osseous matter bordered with two lines of enamel. In proportion as the detrition increases, and descends to the thick part of the eminences, the length of the osseous part increases, and that of the hollows between the eminences decreases. When it advances still more, the anterior hook of the third eminence joins itself to the second, and there remains a ronnd hollow towards the middle of the tooth; a little later another branch of the third eminence unites with the posterior edge of the tooth, and there remains a second hollow behind: these two transverse eminences then unite at their interior extremity, and leave between them a large oval and oblique hollow in the fore part of the tooth. In the last place, wen detrition has procetded to the base of the eminences the hollow's themselves disappear, and the crown then exhibits a smooth surface of osseous matter surrounded by a border of enamel.

One 
One may follow these different states in the figures of Plate . $^{*}$, one of which exhibits the teett of a two-horned rhinoccros still young, the other those of an adult unicorn. One may follow there also the variations of the molar teeth do:vnwards, which are nuch less considerable.

They are composed of two eminences turned round in the form of a portion of a cylinder, and placed obliquely one behind the other, in such a manner that their concavity is turned inwards and a little forwards. The detrition only enlarges the crescents of their summits; but this figure of a double crescent is preserved until the eminences are worn at the base, a period when the tooth becomes quadrangular and single.

It was for want of being well acquainted with this variation of the teeth by detrition, that Merck, to whom, however, we are indebted for the first efforts to illustrate this part of the natural history of the rhinoceros, thought himself authorised to advance, in his third letter on fossil bones, a fact which Faujas inserted in his Essais de Geo-

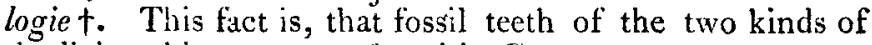
the living rhinoceros are found in Germany.

But, even allowing this fact to be true, it would be impossible to prove it, because the teeth of these two species resemble each other when they are of the same age; but Merck had in his possession the bead of a young two-horned rhinoceros: all the fossil teeth, which resembled those of this head, were considered by him as coming from the twohorned shinoceros, and those which were advanced, from the one-horned.

In reality, these teeth came neither from the one nor the other, as I shall prove hereafter, but from a third species, which differs from the two first in other respects than by the teeth.

We have given in Plate IV. specimens of these fossil teeth of the rhinoceros. It will there be seen, that, without the rules which we have established from observation, every body would be tempted to ascribe them to animals very different.

Fig. 1. represents a superior molar tooth of the right side, very much worn: the original is in our museum.

Fig. 2. exhibits a portion of an upper jaw with two teeth, one of which is entire and still untouched. This fragment, in the cabinet of Joubert, was found near the village of Issel, on the last declivities of the Black Mountain. The individual must have been of a small size.

* Given in our last Number.

II 9

+Vol. i. p. 207. 
Fig. 3. from the cabinet, is one of the lower teeth, also very little worn. It was found in the neighbourhood of Avignonet.

Fig. 4. is the germ of an upper molar tooth nearly similar to those of fig. 2 : it is in the museum, but it is not known in what place it was found.

Fig. 5. a posterior upper molar tooth of the right side, not much worn, from the environs of Canstadt. It was sent to me by $M$. Autenrieth, professor at Tubingen.

Fig. 6 . is the germ of a posterior upper molar tooth of the left side, from the living two-horned rhinoceros.

Fig. 7. an anterior upper molar tooth of a large individual in the collection of the museum : the origin of it is unknown.

Fig. 8. is an inferior molar from the environs of Canstadt. It was also sent to me by $M$. Autenricth.

I shall return to these different teeth in another memoir.

$$
3 d \text {, Of the Vertebra. }
$$

Of these there are 56 in all.

$$
\begin{aligned}
7 & \text { Cervical. } \\
19 & \text { Dorsal. } \\
3 & \text { Lumbar. } \\
5 & \text { Sacral. } \\
22 & \text { Coccygian. }
\end{aligned}
$$

The atlas has its transverse apophyses as large and broad as that of any other animal. They have a hole instead of the indentation at the base of their anterior edge. The spinal is only a large tubercle. Under the body there is a small longitudinal ridge.

The transverse apophyses of the axis are small, and turned backwards : those of the following ones are very broad, and descend towards the ribs: they have three angles, an anterior and two posterior.

The seventh has only a small one which touches the sixth, and which must considerably confine their respective movement.

The spinal apophyses go on increasing: that of the third vertebra is unly $0 \cdot 04$, that of the seventh $0 \cdot 25$.

That of the second dorsal is longer, it is $0^{\circ} 40$; it is besides very thick : they then go on decreasing in length, and becoming fiat on the sides to the thirteenth, which is the lowest, it is 0.12 , and they then again increase. The first lumbar is 0.15 ; the three spinal apophyses of the lumbar are vertical; all those of the back are turned backwards; the transverse apophyses are very short, and present to the tubercles 
tubercles of the ribs facets almost vertical; those of the loins are a little longer.

The five spinal apophyses of the os sacrum coalesce into one ridge. The first six vertebræ of the tail have an annular part, and spinal and transverse apophyses; the other sixteen are merely pyramidal, and go on decreasing in size*.

$$
\text { 4th, The Rils. }
$$

There are nineteen pairs, several of which are real; those of the first pair are united together at the bottom. The sternum is composed of four bones; the first is compressed into the form of a plough-share, and makes a pointed projection before the first rib.

\section{5th, The Anterior Extremity.}

The omoplate is oblong; its greatest breadth is at its upper quarter; its posterior cdge is raised up, and in that place thickened. The ridge has a very prominent apophysis, at the upper third turned a little backwards; it terminates at the lower quarter of the omoplate, consequently there is no acromion: a tuberosity supplies the place of the coracoid beak; the glenoid cavity is almost round.

This form of the omoplate of the rhinoceros will always distinguish it from those of other large quadrupeds; - that of the elephant, for example, is a triangle almost equilateral, and the spine has a large recurrent apophysis.

The humerus is very remarkable, as its thick tuberosity is a broad ridge, which proceeds from before backwards, and as the linea aspera, which is thereby triangular, instead of being linear, terminates at the bottom by a very prominent hook. The anterior extremity of the thick tubcrosity forms a hook forwards; the small produces a simeral one, and between both is a large canal, destined, no doubt, for the passage of the biceps tendon. All these characters will still form a very good distinction between the humcrus of the rhinoceros and that of every other quadruped of its size. The exterior condyle is not very prominent; the other is not prominent at all; the lower articulation is a simple pulley half hollow.

The radius at the top occupies the whole fore part of the fore arm; its head has the form of a simple prominent

* Length from the extremity of the upper jaw to the root of the tail $\quad-\quad-\quad 2.9$

Length from the cervical part of the spine - 0.5

Lengeh from the dorsal part $\quad-\quad-\quad 0.3$

Length from thelumbar part $\quad-\quad 0.2$

Length from the sacral pirt $\quad-\quad-0_{0}$

Length from the coccruigan $\quad$ - $\quad 0.7$

II 3 pulley; 
pulley; it can bend but not turn: at the bottom it becomes nearly as broad as at the top, and terminates in two short apophyses; one anterior, which is pointed, and one truncated; the latter receives the semilunar; between them is a fossa, which receives the scaphoid; its greatest contraction is towards its upper third.

The cubitus, almost every where triangular, has towards the bottom a cavity which receives a projection of the radius; it is terminated by a cavity for the cuneiform bone; the olecraneon is very much compressed, swelled at the end, and forms the fourth of the whole bone*. The carpus is composed of eight bones; the 'scaphoid and unciform are very large; the pisiform is almost round.

On the scaphoid and trapezoid is a bone out of rank, which is analogous to the trapezoid, and the only vestige of the thumb: the semilunar, the great bone, which here is one of the smallest, and the unciform have large protuberances on the palmar facet.

The exterior metacarpian is articulated with the unciform, and has on its interior side two facets for the mean; the latter is articulated with the great bone by a very concave facet, and with the unciform by a small one. The interior is articulated with the trapezoid and the great bone, and touches the middle one by a small triangular facet.

\section{6th, Posterior Extremity.}

The pelvis is exceedingly broad; the wide part of the bones of the ilium being $0^{-5}$ in breadth: its spine is forked, which distinguishes it from the whole series of the bones of the ilium in the elephant: the angle which touches the sacrum is also more elevated; the neck in particular is

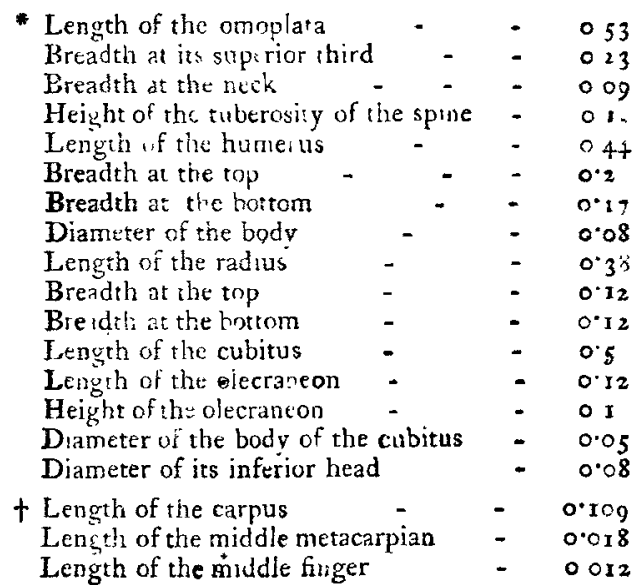


much longer and narrower; it is $\mathbf{0 . 1 5}$ in length and 0.08 in breadth; the exterior edge of this bone is nearly as great as the interior, while in the elephant it is much smaller; the ridge of the pubis begins at the upper part of the neck of the bones of the ilium; the oval formina are broader than they are long; the tuberosity of the ischion is at the top very thick and in the form of a hook.

The femur of the rhinoceros is perhaps still more remarkable than its bumerus; its upper part is very much flattened from before backwards; the eminence, which 1 call the third trochanter, projects very much, and forms a hook which ascends to touch a hook which descends from the common great trochanter, in such a manner that there remains an oval hole between these tivo eminences; the lower pulley is very narrow before; the interior condyle is much more prominent, and ascends higher than the other behind; the two condyles are at a greater distance than they are hefore, but they make nearly the same projection. "The head of the tibia is an equilateral triangle, only the interior posterior angle forms a very strong tuberosity below the rotula. The lower part of the tibia is a little flattened from behind backwards; the perone is slender, compressed laterally, and swelled at its two extremities*. The calcaneum is thick and short; its anterior or astragalian face is triangular. There are two large facets for the astragalus; that of the interior sides is lengthened into a kind of tail along the lower edge of that face. In my opinion this is a character proper to distinguish the species. "The facet which touches the cuboid is very small; the facets of the astragalus are $a$ coutiterpart of those of the calcaneum; the two edges of its pulley are of equal height; the part of the anterior face, which touches the cuboid, is narrow.

The cuboid has behind a long and thick protuberance; on the interior side of the foot there is a similar production by a supernumerary bone attached to the scaphoid, to the interior cuneiform, and the interior metatarsian; the scaphoid then has three articular facets on its anterior fice; the interior cuneiform is much smaller than the other.

$\begin{array}{lll}\text { * Length of the femur } & - & 0.5 \\ \text { Its breacith at the top } & - & 0.2 \\ \text { Breadth } ; \text { the bottom } & - & 0.15 \\ \text { Length of the tibia } & - & 0.4 \\ \text { Jts breadth at the top } & - & 0.14 \\ \text { Breadth at the bottom } & - & 0.11 \\ \text { Diameter of the body } & - & 0.09 \\ \text { Length of the perone } & - & 034 \\ \text { Breddth at theootsm } & - & 0.05\end{array}$


The exterior metatarsian articulates only with the cuboid, and touches by two facets of the exterior edge of its head the middle metatarsian; the latter is articulated only with the great cuneiform, and by the exterior to the supernumerary bone, for which it has only one facet.

The phalangia are broader than long*.

XIX. Olservations on the Electricity of Metallic Sulstances, By M. HauY t.

$T_{\text {HE different methods of exciting in bodies the electric }}$ virtue, furnish characters from which great advantage might be derived in regard to the distinction of minerals; the most remarkable is that which results from the electricity produced by heat, and which hitherto has been observed only in six species of minerals, viz. tourmalin, borated magnesia, topaze, mesotype, phrenite, and oxidated zinc. Another method of exciting the electric virtue consists in friction, to which idio-electric substances are subjected. This virtue, as is well known, is of two kinds; one which we call vitreous electricity, and which belongs in general to earthy and acidiferous substances, and another distinguished by the name of resinous electricity, and which characterizes more particularly non-metallic combustible substances, the diamond excepted, the electricity of which is vitreous. Other substances are non-electric, and, to acquire the electric virtue, have need of being brought into communication with a conductor already endowed with that virtue. Metals in the metallic state possess, in an eminent degree, the faculty of becoming electric in this manner, which may be employed to detect a metal concealed in a stony substance. This is the case with iron, which enters into the composition of jasper, and the presence of which is announced by the sparks emitted by the stone on the finger being applied to it, while it is in contact with an electrified conductor.

I conceived the idea of employing in another manner the electricity of metallic substances, by insulating them, and rubbing them over an idio-electric substance. The latter then acquires an electricity, the kind of which varies according to the nature of the metal used as a rubber; and by

* Length of the calcaneum at its extcrior edge - 0.13

Breadth of it articular fice - - $\quad 0 \circ 9$

Breadth of the astragalus - $\quad 0.08$

Length of the middle bone of the metatarsus - 0.165

Length of the middle finger - - $0 . \mathbf{I I}_{\mathbf{r}}$,

+ From Inwales du Museum Nuicnal d Histoire Naturelle, No. 7 . 